\title{
A model of light interception and carbon balance for a sweet chestnut coppice (Castanea sativa Mill.)
}

\author{
L. Mordacq and B. Saugier
}

Laboratoire d'Ecologie Végétale (CNRS URA121), Bât. 362, Université Paris-Sud, 91405 Orsay Cedex, France

\section{Introduction}

Data have been collected on leaf photosynthesis, young tree photosynthesis, wood respiration and aerial growth in a sweet chestnut (Castanea sativa Mill.) coppice for several years after a cut. We designed a model to predict photosynthesis of heterogeneous canopies and wood respiration. The output of the model together with measurements of aerial growth enabled calculation of the amount of carbon allocated to roots.

\section{Materials and Methods}

Leaf photosynthesis has been measured in situ on attached leaves using a laboratorymade assimilation chamber with control of leaf temperature by Peltier elements. The chamber was working as an open system and the leaf temperature was fixed at $24^{\circ} \mathrm{C}$. Measurements were made throughout the growing season.

Tree photosynthesis was measured in situ on a $1 \mathrm{yr}$ old chestnut tree using a large assimilation chamber $(0.9 \mathrm{~m} \times 0.9 \mathrm{~m} \times 1.8 \mathrm{~m}$ high) built in the laboratory and working as an open system. A high flow of air through the chamber (maximum $0.08 \mathrm{~m}^{3} \cdot \mathrm{s}^{-1}$ ) kept the increase in air temperature within $4^{\circ} \mathrm{C}$ with respect to the outside (Mordacq and Saugier, 1989). Measurements were performed at the end of the growing season during August and September.

The assimilation model took into account the heterogeneous structure of the canopy, which is necessary during the first years after the cut. Each tree was first considered as being isolated; there was no intersection between the foliage of different trees until the end of the first year. The leaves in the model were distributed homogeneousiy within ellipsoids or fractions of ellipsoids around each stump. The dimensions of the ellipsoids were measured in situ and the trees were distributed randomly on the soil surface, except that there could be no intersection between the ellipsoids at the end of the first year. The light penetration was calculated at randomly distributed points $P$ by calculating the extinction coefficient from the leaf angle distribution (de Wit, 1965), and the pathlength (Fig. 1) of light rays $R$ through the ellipsoids (Norman

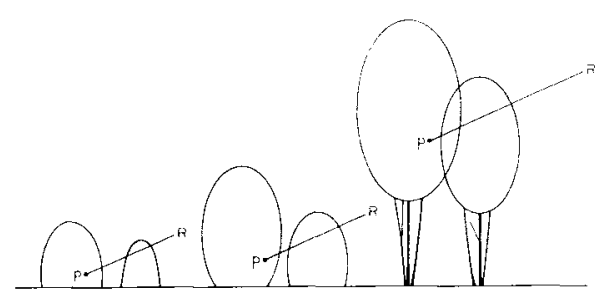

Fig. 1. Representation of the path of light rays in the 'modelled' heterogeneous canopy. 
and Welles, 1983). Diffuse light was treated as direct light and integrated over the whole sky. Thus the model enabled calculation of shadowing between trees. As the trees grew, the ellipsoids grew to the point where the soil was completely covered by the canopy (Fig. 1). Photosynthesis was calculated on an hourly basis.

\section{Results}

Fig. 2 shows measurements made on mature chestnut leaves. The light satura-

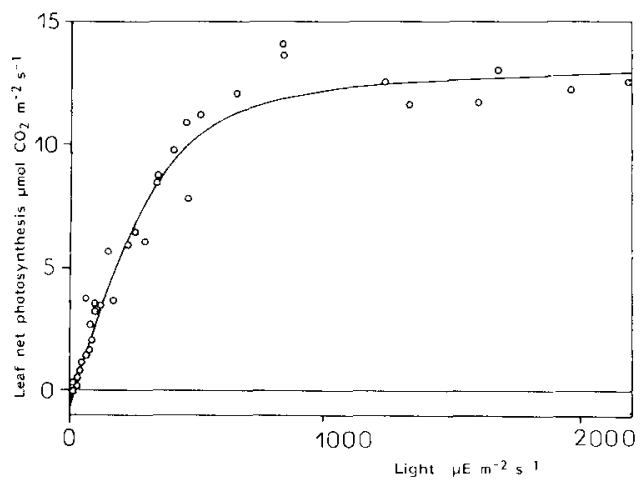

Fig. 2. Leaf photosynthesis light response measurements at a leaf temperature of $24^{\circ} \mathrm{C}$.

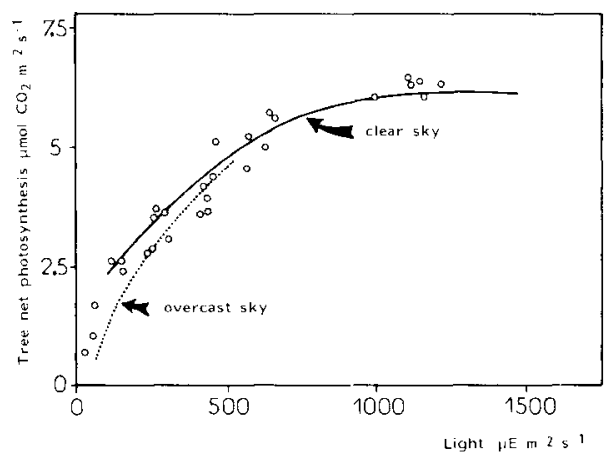

Fig. 3. Tree photosynthesis-light response. Measurement points are compared with model outputs (solid and dotted lines). tion level was $600 \mu \mathrm{E} \cdot \mathrm{m}^{-2} \cdot \mathrm{s}^{-1}$; the maximum photosynthesis level was $13 \mu \mathrm{mol}$ $\mathrm{CO}_{2} \cdot \mathrm{m}^{-2} \cdot \mathrm{s}^{-1}$.

Fig. 3 shows the tree photosynthesis-light curve (by unit leaf area of the tree) compared with the outputs of the model for a single tree and for two light conditions. The light saturation was at $600 \mu \mathrm{E} \cdot \mathrm{m}^{-2} \cdot \mathrm{s}^{-1}$ and the maximum tree photosynthesis level was $6 \mu \mathrm{mol}$ $\mathrm{CO}_{2} \cdot \mathrm{m}^{-2} \cdot \mathrm{s}^{-1}$, about half of the maximum leaf photosynthesis. Agreement between measurements and model outputs is good. However, at low light levels, the model underestimated photosynthesis for overcast sky conditions and overestimated it for clear sky conditions.

\section{Conclusion}

In its present form, the model does not account for assimilate partitioning. We used it to derive a carbon balance of the

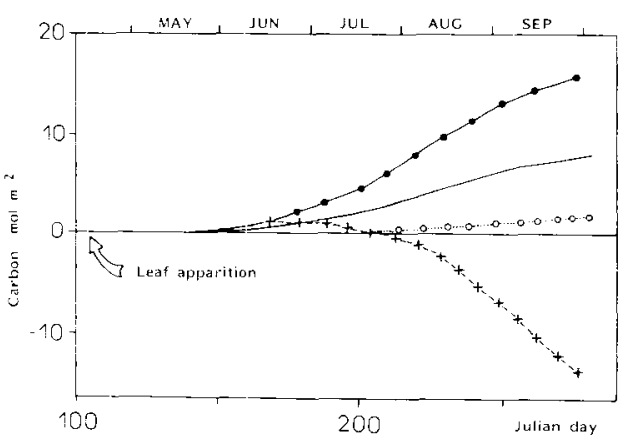

Fig. 4. Carbon balance of the coppice during the $1 \mathrm{st}$ yr as estimated from the difference between predicted cumulative net $\mathrm{C}$ assimilation, and the sum of calculated shoot (growth and maintenance) respiration and biomass accumulation (see text). _-._: aboveground biomass (measured); --+-: carbon allocated to roots (accumulated); - - aboveground growth respiration (accumulated); $\cdots 0 \cdots$ : aboveground maintenance respiration (accumulated). 
stand, computed as the difference between net assimilation (predicted) and total (growth and maintenance) shoot respiration (measured and fitted to temperature). The allocation of carbon to roots was tentatively computed as the difference between the net amount of carbon entering the plant and the measured amount of carbon stored by the shoots during growth. Fig. 4 shows these various components. Roots apparently act as a source of carbon from early spring until mid-July, which is confirmed by measurements showing a strong decrease in root starch concentration during that time (Dubroca and Saugier, 1988). Later on they become a strong sink and, at the end of the season, the accumulated amount of carbon allocated to roots is similar to that stored in shoots.

\section{References}

de Wit C.T. (1965) Photosynthesis of leaf canopies. Versl. Landbouwkd. Onderz. (Agr. Res. Rep.) 64, 57-67

Dubroca E. \& Saugier B. (1988) Effet de la coupe sur l'évolution saisonnière des réserves glucidiques dans un taillis de châtaigniers. Bull. Soc. Bot. Fr. 135, Actual. Bot. 1, 55-64

Mordacq L. \& Saugier B. (1989) A simple field method for measuring the gas exchange of small trees. Funct. Ecol. in press

Norman J.M. \& Welles J.M. (1983) Radiative transfer in an array of canopies. Agron. J. 77, 481-488 